\title{
Emotional Intelligence, Depression and Psychological Adjustment among University Students in the Sultanate of Oman
}

\author{
Suad M. A. Sulaiman ${ }^{1}$ \\ ${ }^{1}$ College of Education, Sultan Qaboos University, Muscat, Oman \\ Correspondence: Suad Sulaiman, Department of Psychology, College of Education, Sultan Qaboos University, \\ Muscat, Oman. Tel: 968-9-944-4646. E-mail: dr.suad.sulaiman@gmail.com
}

$\begin{array}{lc}\text { Received: June 11,2013 Accepted: August 7, } 2013 \quad \text { Online Published: August 15, } 2013 \\ \text { doi:10.5539/ijps.v5n3p169 } & \text { URL: http://dx.doi.org/10.5539/ijps.v5n3p169 }\end{array}$

\begin{abstract}
The study aimed to investigate the relationship between emotional intelligence (EI), depression and psychological adjustment in relation to gender among Sultan Qaboos University (SQU) students. The study sample consisted of 323 students all of whom have completed answering the EI inventory, Beck's list for depression and the psychological adjustment interment. In addition, T-test were conducted to detect the differences between males and females regarding emotional intelligence means (high, low) upon the means of depression and adjustment. The research showed a high level of EI among SQU students; a higher EI average for female students compared to males; a negative correlation between EI and depressive symptoms and a positive correlation between EI and psychological adjustment.
\end{abstract}

Keywords: Emotional Intelligence (EI), depression, psychological adjustment, gender, university students

\section{Introduction and Literature Review}

The importance of feelings and emotions and their impact on people's lives is a new trend that has recently been in the forefront of people's lives as they try to deal with their environments (Salovey, 2001). As a result, new research has experienced a shift in focus from behaviors, ideas and cognitive processes to emotions (Heesacker \& Bradley, 1997). Consequently, emotional disorders have become the key element and the basis of psychological health (Kring \& Bachorowski, 1999). The focus of modern theories is on emotions and self-regulation, and they also refer to the tensions and psychological stress which people go through in their daily life. Emotions raise some issues and threats that may affect the health of people. These threats may affect people's physical, psychological or social welfare (Edwars, 1998).

The concept of EI emerged in the field of psychology at the end of 1930 when Thorndike wrote about social intelligence and defined it as "the ability to understand and manage social relations and the ability to behave wisely with others" (Gardner, 2000). Since then, many psychologists have shed light on cognitive dimensions like memory and problem solving, while few have focused on emotions.

Emotions are considered a source of psychological adjustment and a protection from physical pain as well as being the facilitator and maintainer of self-identity in social events. They also direct a person to accomplish goals and succeed (Oaltey \& Jenkins, 1998). EI has a great impact on psychological stress because of negative results and the failure the person might face as a result of this stress. Therefore, EI is a way people can control the emotions that cause stress and deal effectively with other peoples' emotions. Although, EI is not just about emotions; it is a combination of emotions, feelings, thoughts and behaviors (Vander Voort, 2006).

In the past, psychologists have tried to understand the strength of the relationship between some psychological functions and EI. They found that the acquisition of EI has a positive impact on being successful in life (Parker, Summerfelds, Hogan \& Majeski, 2004; Vakola, Tsaousis \& Nikalaou, 2004). Now, after discovering this relationship and its impact, there is a considerable increase in the interest of how we interact and the impact of psychological experiences on general health. It has become certain that there is a beneficial impact of positive emotions on raising the efficiency of the immunity system, in contrast, there is an unfavorable impact of negative emotions on psychological functions. (Herbert \& Choen, 1993). Moreover, high attention to feelings, but low in emotional clarity and repair result in poorer psychological adjustment, higher levels of anxiety, depression, and social stress, and lower level of general mental health (Salguero; Palomera \& Fernandez-Berrocal, 2012). 
EI is defined as the ability to know and interpret emotions and to recognize their significance and relation to problems, including their causes and solutions (Mayer \& Salovey, 1990). However, the best definition of EI is the accepted definition of Salovey \& Meyer (1990): the process of dealing with emotions including the ability to have appropriate responses to show emotions and expression, both with the same person or with others. All this happens while trying to improve the level of life through the acquisition of the capacity to adjust to those emotions. It is one of the forms of social intelligence, which includes the ability to recognize and discriminate between your and others' feelings and utilize this knowledge in your intellectual, emotional and physical behavior.

Individuals differ in the level of skills that will help them to understand their feelings and the emotions of others, and then organize these sentiments and excitements and make use of them in raising the level of cooperative behavior. The organization of these skills and putting them into a practical framework is called "emotional intelligence" (Salovey \& Mayer, 1990). Pellitteri (2002) has designed a conceptual model that is composed of three key elements of EI:

1) Emotional awareness, refers to the ability of the individual to know his/her emotions and reactions of others, being aware of them, and the ability to distinguish between negative and positive expressions of others.

2) Emotional self-regulation, refers to the ability of the individual to control and use his/her behavior and the meanings and expressions of others.

3) Emotional knowledge, refers to the individual's understanding of his emotions and others'. It also includes the use of emotions and emotional knowledge to draw attention to and to focus on the important area of social life, in order to develop creative and flexible views as well as to maintain the level of motivation to achieve positive goals.

In addition to these three components, Richburg and Fletcher (2002) added two dimensions: First, the ability to control the emotions and management. This is key to increasing the level of self-awareness, and aims to acquiring the skills that help in dealing with fears, anxiety, anger, and sadness. The second dimension is social skills, and dealing with others; it means the ability of the individual to maintain social relations.

To activate and improve the educational process, it is important to include various factors of EI in educational curricula and courses in schools and institutions of higher education. In addition, social skills and training of teachers and students is needed. EI does not only facilitate learning processes, but it also improves the skills and capabilities of individual choice and success, and contributes to the adjustment in various aspects of life, including adjustment to university life (Khawaldeh, 2004).

People are usually expected to talk less about their negative emotions, such as psychological pressure, anxiety, depression, fears, anger, guilt and shame (Lazarus \& Folkman, 1987). The theory of analysis of interaction adds an importance to the role of individual differences in order to understand why some people respond and interact with less skill than others when they face the same circumstances and psychological stress (Cox, 1993). There are many studies which attribute those differences to personality types and variables, optimism, pessimism, and others (Spector \& Oconnell, 1994). In addition to the personal features, psychologists are aware of the importance of functions in attitude toward others, including social support, and interpersonal skills. This means social and emotional skills which affect our reactions to threats. These functions are the same as EI (Slaski \& Cartwright, 2003)

We can conclude that EI in effects the individual with psychological disorders like depression, anxiety, and poor psychological adjustment and other psychological disorders. Depression is the second most widespread psychological disorder after anxiety. It is the disorder that shows symptoms on many individuals who seek psychological services. The symptoms of depression appear in all ages, in particular to individuals in adolescence, and more in females. The degree of depression ranges from simple depression to severe depression (Dahadhah, 2008).

Due to the fact that EI is part of the wide social, psychological and emotional dimensions, it undoubtedly affects the mood of the individual, and his/her feeling of comfort and happiness. Therefore, it is a skill that may help in reducing the feelings of depression or anxiety and improve psychological adjustment skills and with life in general.

The feeling of depression indicates recruit weak social skills. Sadness differs from depression in term of the severity and continuity of sadness does not continue with the same intensity and does not disrupt human life. It is possible to turn into to depression at any moment. For example, when a person loses someone dear to them (Rowe, 2001) the depressed person does not exercise any kind of activities related to entertainment. To him/her, 
love, hobbies, and entertainment are all things that do not appeal to him/her; s/he is also inclined to withdraw from his/her duties and responsibilities. S/he criticizes him/herself and thinks about death and suicide. This is difficult to natural feeling of sadness which does not affect normal functions of the individual where the intensity is lighter and does not continue for a long period (Al- Rihani, Hamdi \& Abu Talib (1989).

Psychological adjustment to university life relates to depressive symptoms. Whenever there is a high level of psychological adjustment, there is less symptoms of depression. Wolman (1989) defines the psychological adjustment as an adaptive relationship with the environment and the ability to meet the individual's needs and to meet most social and psychological requirements. Brodsky (1988) explains that the process of psychological adjustment means normality, internal psychological adjustment, social sufficiency and controlling changing requirements. As for normality, it means the absence of problems that result from internal situation of the individual or the external social environment. Internal psychological adjustment can only be achieved when the individual is free from internal conflicts between specific needs and values.

Cognitive theory defines the subject of psychological adjustment, as suggested by Ellis, when the individuals who are psychologically adjusted think logically, rationally and scientifically which prevents the emergence of psychological disorders (Sulaiman \& El- Mensal, 1998; Derlega \& Janda, 1986).

\subsection{Previous Studies}

The relationship between EI and psychological disorders and their impact on adjustment and the level of psychological and physical health had been studied in adults and adolescents. There are four models or EI factors associated positively with satisfaction in life (Saklofske, Austin \& Minski, 2003). Many studies which examined the relationship between EI and depression, indicated that the individuals who scored high degrees on the dimensions of the EI scale showed higher levels of satisfaction with their life (Martinez-pons, 2003; Ciar-rochi, Deane \& Anderson, 2002), a high level of consensus (Martinez-pons, 2003), and low depression levels (Martinez-pons, 2003; Saklofske, Austin \& Minski, 2003; Ciar-rochi; Deane \& Anderson, 2002). Most of this research indicates that there is a clear impact of prominent EI in the success of the individual professionally and socially. On the other hand, people who have demonstrated a low level of EI showed weak skills in consensus in social, emotional, and professional (Salovery et al., 2001; Salovery, 2001).

A study, undertaken by Ghorbani, Mark, Kristl, and Dan (2002) entitled Self-reported emotional intelligence: construct similarity and functional dissimilarity of higher-order processing in Iran and the United States consisted of (231) Iranian and (220) Americans university students. They responded to a scale feature moods to assess cross-cultural EI. This was a response to answers on the Richter depression and anxiety inventory and the concept of self-reliance and the self-awareness. The results showed that most measures linked negatively with EI for the study participants from both samples except for self-awareness scale and the concept of self-reliance scales. Moreover, student from both countries showed positive link with the emotional intelligence.

Another study was conducted by Tsaousis and Nikolaou (2005) entitled Exploring the Relationship between Emotional Intelligence and Physical and Psychological Health. The study encompasses perception variables, control, understanding emotions and psychological health which included depression and anxiety, as well as physical health. The study consisted of two parts, the first based on a sample of (365) individuals, the second part was on a sample of (212) individuals. The participants answered the EI inventory, and the general health and psychological health standards. The results indicated that there is a positive relationship between EI and psychological health including overcoming feelings of depression and anxiety, while there was a negative correlation between emotional intelligence, smoking and alcohol.

In order to measure EI skills, social skills and psychological stress between gifted students in Hong Kong, Chan's (2005) study included a sample study of (624) talented students, who controlled tests of EI and psychological stress, including depression. The results showed that EI was a social skill used by the talented students in order to face psychological stress. The study recommended the importance of training students to acquire EI skills was to develop social skills in order to be able to reduce stress.

Ghorbani (2006) carried out a study entitled religious orientation types in Iranian Muslims: differences in alexithymia, emotional intelligence, self-consciousness, and psychological adjustment. The study included 191 students, who answered the EI inventory, self-awareness scale and psychological adjustment measurement as well as depression and anxiety scales in Tehran University. The study proved that religious sectores don't have a big effect. It also showed that there are differences in EI and self-awareness. It concluded that psychological health doesn't depend on a specific religion or a culture.

Amitay and Mongraion (2007) tried to identify personal relationships in terms of EI with a group of people who 
had depression. The researchers assumed that people with good levels of EI are more capable of getting along with partners. The study sample consisted of (58) graduates who had a history of depression according to the diagnostic statistical manual of psychiatry, using Mayer's scale of EI (Mayer, et al., 2002). The study concluded that people who have high EI are less critical and rejecting of their partners compared to those who scored low levels of EI. In addition, people with high EI showed great support to partners, self-consciousness and openness to previous experiences.

In a study Mavroveli and his team (2007) investigated the relationship between trait emotional intelligence, psychological well being and peer-rated social competence in 282 Dutch adolescents. The result showed trait emotional intelligence was positively associated with adjustment coping styles and negatively associated with maladjustment coping styles, in boys only. Moreover, Adolescents with high trait emotional intelligence received more nominations from their classmates for being co-operative.

Jacobsen and his team (2011) conducted a study on a large group of high school students, the sample included 2189 adolescents. The researcher investigates the correlation of depression and suicidality by assessing the relationship between restrictive emotionality (difficulty understanding and expressing emotions) and depressive symptoms and suicidal ideation and attempts among adolescents. The findings of the study revealed restrictive emotionality is highly associated with depressive symptoms and suicidal thoughts and behaviors among high school students.

In a study the researchers investigated the predictive validity of perceived emotional intelligence (attention to feeling, emotional clarity, and emotional repair) over psychological adjustment in an adolescent sample, that perceived emotional intelligence is a stable predictor of adolescent adjustment and may serve as useful resource for preventive interventions (Salguero, Palomera \& Fernandez-Berrocal, 2012).

Most of these studies agreed that EI has a great impact on the level of depression and psychological adjustment and is the key element in dealing with emotions, whether negative or positive.

\subsection{The Research Problem}

The Students' Counseling Center at SQU tries to help students in many aspects of life including adjustment to life at Sultan Qaboos University by reducing the psychological, academic and social problems they may encounter. In addition, it enhances the level of learning and provides students and teachers with appropriate studying skills and strategies. In view of the great importance of EI and its strong link with depression and feelings of maladjustment, the researcher noticed that students who cannot adjust might go through depression as well. This is due to lacking of appropriate ways to deal with feelings, social skills and understanding other people feelings i.e., EI. To confirm the relationship between these concepts, this study tried to find the link between EI, psychological adjustment and depression. If this relationship is proven, this will help improve training programs on EI skills to reduce depression and improve the level of psychological adjustment with university life in general.

\subsection{The Significance of the Research}

The aim of the study was to find the relationship between EI and two variables, depression and psychological adjustment. This study depends on hypothesis that EI includes the intelligent dealing with both negative and positive emotions and the positive ones. The study gains its importance from focusing on key concepts that are relevant to the students' university lives and affect their study. Hence finding the factors responsible for moods and maladjustment will be the best strategy and therapy to limit those problems. This as a result, will raise the efficiency of the Students Counseling Center. The results will contribute to good planning for the center's programs and for applying new training programs based on EI skills in the future.

In addition, the study is important because it applies EI inventory which have been introduced to SQU students. These scales attribute the results into qualities and quantities. In this test, the student can put his/her results on both sides of the scale and then identify his situation and explain the characteristics of that situation. Students who participated in using this scale in developmental guidance lectures provided positive feedback (Al-Dahadhah \& Sulaiman, In press).

Svyantek and Rahim (2002) noted that EI is an important strategic skill that helps people to deal with others surrounding them. EI is considered to be twice as important as mental intelligence because it includes skills that can help in achieving professional, social and academic success (Golman, 1998).

It is anticipated that people who get high scores on the EI scale will show low scores on Beck's inventory for depression (Bulik, 2005) and high scores in the psychological adjustment scale. This can be explained through the following figure. 


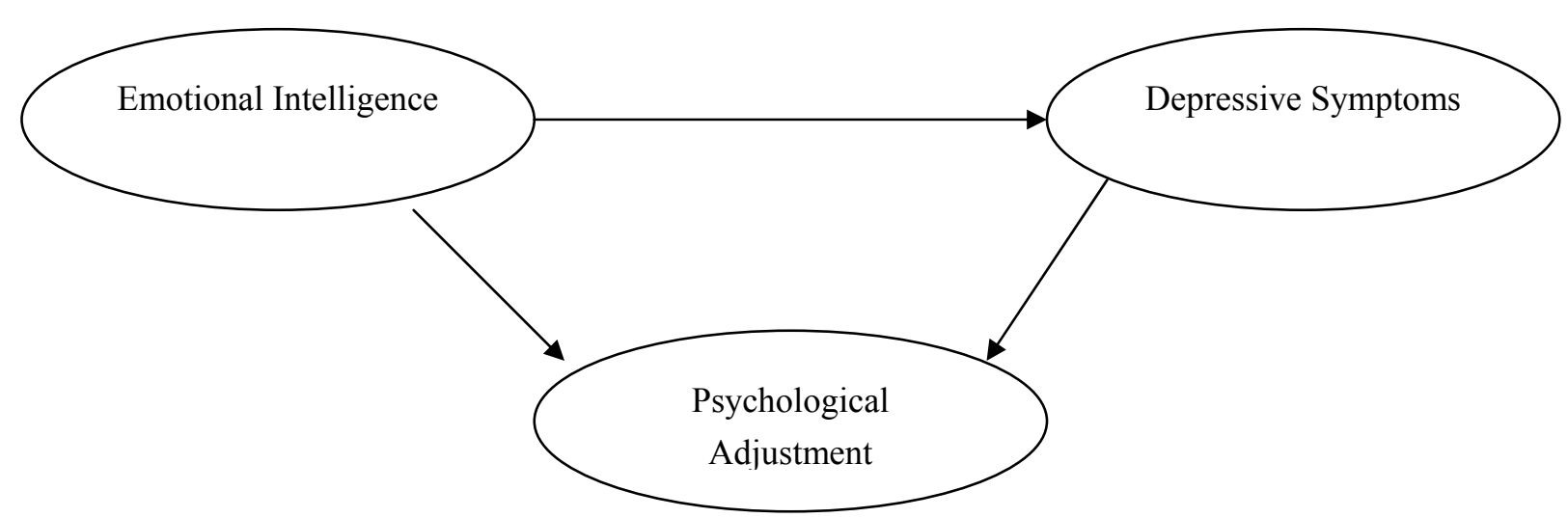

Figure 1. The relationship between depression symptoms, EI and psychological adjustment

The previous figure indicates that EI affects the possibility of depression and the psychological adjustment. On the other hand, depression also affects the psychological adjustment. This means that psychological adjustment is affected by both the level of depression and EI score.

\section{Research Questions:}

The study attempted to answer the following questions:

1) What is the average level of EI amongst SQU female and male students?

2) Is there any connection between EI, depression and psychological adjustment?

3) Is there any effect of gender on EI?

4) Is there any effect on depressive symptoms that can be linked to the level of EI?

5) Is there any effect on the level of psychological adjustment that can be connected to the level of EI?

\section{Terminology:}

For this study, there are some terms that may occur:

EI: refers to 'the process of dealing with emotions which include appropriate reactions in showing emotions and expressing them, whether with the individual him/herself or with other people in order to improve the level of life through acquiring the ability to get along with these emotions.' It is a form of social intelligence which includes the ability of monitoring your own feelings and other people's feelings and applying this knowledge behaviorally, intellectually, emotionally and physically (Salovey \& Mayer, 1990). It is defined in this study as the EI scale which was prepared for this purpose.

Depression: Beck defines depression as "the negative thoughts one has about himself, the others and the future. These thoughts are responsible for explaining the experiences, events and feelings "(Watkins, 1997). In this research, depression is referred to by students' scores using the Beck Depression Inventory.

Psychological adjustment: is an adjustment with the surroundings which offers the ability to satisfy most social and psychological needs. In this research it is defined as the score the students attain in the psychological adjustment instrument.

\subsection{Limitations of the Study}

The research was carried out according to the following determinants:

1) The research used three tools: EI scale, the psychological adjustment instrument and the Beck Depression Inventory. These scales were tested on a group of students in SQU. Therefore, the results of this study are affected by these scales and their authenticity in measuring these elements.

2) The findings will be affected by the sample chosen, which are SQU students at different levels. So the results will be generalized for them only.

\section{Population and Sample}

The studies population was from Sultan Qaboos University. The sample of the study consists of 323 students, 
164 males and 159 females. Those were chosen randomly by inviting them to public lectures carried out at the Students Counseling Center or by approaching them individually.

\section{Study Tools}

\subsection{Firstly: EI Scale}

Wakeman's scale (2006) was translated into Arabic. The same methodology was used to assure reliability and validity and to suit the Omani environment. In its final version, the scale consisted of three elements:

Part one: Includes general information about the participants.

Part two: Includes the parts of the scale which consisted of (40) parts divided into two sub categories which are:

1) Emotional self-management: This scale measured self-confidence, self control, initiative, self consciousness, independence and emotional awareness. The positive indicators were reflected in items 1,8,11,19,20,24,26,34,37 and 40 ,whereas $3,27,23,16,9,6,31,35,39$ reflected the negative indicators of the scale.

2) Social skills: This scale measured leadership, conflict management, effective communication, compassion, group work ethics and personal relationships. These were measured through the positive points $4,5,10,13,14,22,29,30,33,36$ and the negative points $2,7,12,18,21,25,28,32,38$.

Part three: Correcting the scale.

After reading the statements, the student chose the appropriate answer for him/her. 1 was given for yes and zero was given if the answer did not into consideration the negative and positive statements when collecting data. Getting (0-20) represents a low EI which was under (50\%) of the entire study sample. Conversely, a high EI was defined as (21-40). Two methods were used to get the results. The first one was quantitative correction. The second one was qualitative which required justification and explanation of strengths and weaknesses according to the different dimensions of the scale.

\section{Scale Reliability}

To assure the stability of the scale, it was given to (64) students (38 males and 26 females). They were asked to answer the statements in the scale. Then the internal consistency coefficient for their responses was measured using Cronbach's alpha equation with a whole value which reached (0.92). Moreover, the reliability coefficient was reached by repeating technique, that is by applying the scale on a sample that consisted of (25) male and female students after a time gap of two weeks between the first and the second measurement. The results revealed the reliability coefficient on the bases of the whole scale equaled (0.87). Accordingly, we can reach a conclusion that EI scale had an acceptable degree of reliability which justifies the use of this scale to conduct more studies and for other practical and diagnostic applications.

\section{Scale Validity}

The researchers ensured validity of the study by showing it to 13 experts in counseling, measurement and assessment in the College of Education and the Students Counseling Center at SQU. These experts were asked to assess the statements of the scale regarding clarity and consistency in addition to modifying the statements where necessary. The statements were modified in terms of the language only. Moreover, to ensure the authenticity of the scale, it was applied to 34 students who are visiting the students counseling center in SQU in order to find out the ability of the scale to identify differences between the students in relation to their social skills and having EI. The tool identified the students who suffered from psychological problems correctly.

To identify the ability of the scale in differentiating between the students according to their age, this tool was applied to a random group consisting of (246) students and employees at SQU. The test represented 4 age groups. The analysis showed that there are differences in the average EI amongst the four groups. Through comparing the dimensions of self emotional management and social skills the results were in favor of the older participants. The result showed that the scale has the ability to differentiate between participants according to their age.

To fully ensure that the scale measures two different domains, the correlation coefficient measurement was conducted between the domains of the scale on a sample of (48) students. The correlation coefficient was found to be $(0.76)$ for the domain of emotional self-management and $(0.89)$ for the domain of social skills. These measures are enough to ensure the reliability of the scale.

\subsection{Secondly: Psychological Adjustment Instrument}

Sulaiman's adjustment instrument (1996) for the Omani environment was used in this study. The scale had (58) parts divided into four sub dimensions as following: 
1) The first dimension includes psychological, personal adjustment. It measures depression, anxiety, loneliness, self-esteem and physical and psychological health, and consisted of (20) elements tested by the following statements $(7,8,13,14,25,26,27,31,33,34,36,42,43,44,47,49,50,54,56,58)$

2) The second dimension: psychological family adjustment: it measures independence, family relationships, parents' support involvement in family and social life and social satisfaction. This part consists of (20) elements including the following statements $(1,5,11,15,17,18,21,32,37,38,41,48,53,57)$.

3) The third dimension: Psychological academic adjustment: measured the academic efficiency, academic barriers that one may face as well as satisfaction of his /her major and future profession. This part included (12) statements: $(6,9,19,22,23,28,29,30,35,39,45,52)$.

4) The fourth dimension: psychological, social adjustment: measured social integration, social involvement, social relationships and social support. It consisted of (12) statements $(2,3,4,10,12,16,20,40,46,51,55)$.

Sulaiman (1996) extracted signs on the authenticity of the scale which first consisted of (246) items. It was shown to experts in the College of Education and Islamic Sciences at SQU in order to judge the connection between the statements and the dimensions they were to measure. Some items were excluded and some statements were modified. As a result of the feedback also from 30 students, the scale consisted of 189 items.

Factor analysis results on sample of 400 students revealed the construct of the interment consist of four dimensions. The final instrument included 58 items. To ensure that the instrument measures four different dimensions, the correlation coefficients among them was calculated and found to be between $(0.49-0.60)$. This indicates the construct validity of the scale.

Regarding the consistency of the scale, Cronbach's alpha was used to find the reliability coefficients for the different dimensions of the scale. It was found that the internal consistency of the different dimensions of personal, familial, academic and social psychological adjustment were $0.88,0.87,0.81$ and 0.80 respectively. For the whole interment, the internal consistency was 0.81 . The reliability coefficient for the whole scale $(0.81)$ was also found by using the results of the test-retest correlations. The scale was used with another sample consisting of 37 male and female students two weeks after the first test.

As a result, we can say that the psychological adjustment scale has a high degree of authenticity and validity for these participants which justifies choosing it for the study.

Regarding the correction process, every point of the scale included five gradual degrees (always, usually, sometimes, rarely, never) and they are based on Likert scale. They were given the following degrees for the positive points: always $=5$, usually $=4$, sometimes $=3$, rarely $=2$, and never $=1$.

For the negative points, the previous degrees were reversed as follows: always $=1$, usually $=2$, sometimes $=3$, rarely $=4$, and never $=5$. The total positive points were (25) points, while the negative ones were (33) points. The degree on the whole scale is approximately (58-290). The maximum degree represented (290) the highest degree of psychological adjustment, while (58) represented the lowest degree of psychological adjustment.

\subsection{Thirdly: Beck Depression Inventory}

This inventory is considered a well-known and successful scale to measure the level and type of depression. This scale was created by Beck, an American scientist and psychiatrist, professor at the University of Pennsylvania. This scale was translated into Arabic by Hamdi and his fellows (1988). This list consists in its original form of (21) points which were ordered according to their intensity of display starting from "it does not exist" to "it does exist". This was represented in numbers (0-3). (0) represented 'no display' while $(1,2,3)$ represented the gradual levels of depression as they increased (Beck, 1979).

\section{Population and Sample: Evidence of Reliability and Validity}

Hamdi et al. (1988) investigated the reliability of the Arabic version of Beck Depression Inventory. They took a sample of (56) male and female students at the Jordanian University and divided them into two groups: a depressed group and a non-depressed group based on clinical interviews. The students were given the Arabic version of the Beck Depression Inventory. The results had static significance at the level of $(\alpha=0.001)$ in terms of distinguishing those who were depressed and those non-depressed. Regarding the consistency of the Arabic version of the Beck Depression Inventory, the test was given a week later to a sample of (80) male and female students at the Jordanian University. The results showed that the reliability factor was (0.88). The internal consistency of the Arabic version was also measured on a third sample which consisted of (635) male and female students using Cronbach's alpha at a value of (0.87).

The psycho meter features of the list on this study were given to referees: (5) were PhD holders, and (4) MA 
holders recommended adjusting point (21) to fit with the social standards. Other than that, they recommended keeping the Arabic version of the list as it is as it is considered one of the most important scales concerned with normal people and mental patients. For the purpose of this study, the factor of reliability was measured using the internal consistency with Cronbach's alpha on a sample of the study: (60) male students and (73) female students. The value was (0.87).

\subsection{Correcting the Tool}

The list was corrected by collecting the grades that the person attained on all the points. This grade ranged on the list between (0-63) and it is interpreted on the list as follows: First: not depressed (0-11). Second: light depression (12-17). Third: medium depression (18-25). Fourth: severe depression (26-63). As Beck stated (10) is the separating point that distinguishes depressed and non-depressed individuals.

\section{Results and Discussion}

To answer the first question relating to the average level of EI for male and female students at SQU, the means and Standards Deviations have been measured for the males and females on the EI and Psychological adjustment as Table (1) shows:

Table 1. Mean and standard deviation values of EI, depression and psychological adjustment of males and females

\begin{tabular}{lllll}
\hline Type & Variable & $\boldsymbol{N}$ & $\boldsymbol{M}$ & $\boldsymbol{S D}$ \\
\hline Male & EI & 164 & 22.05 & 4.23 \\
& Depression & 164 & 22.57 & 9.49 \\
Female & Psychological Adjustment & 164 & 111.85 & 28.99 \\
& EI & 159 & 26.92 & 5.98 \\
& Depression & 159 & 12.07 & 4.45 \\
The whole & Psychological Adjustment & 156 & 160.36 & 36.94 \\
& EI & 323 & 24.45 & 5.71 \\
& Depression & 323 & 17.40 & 9.11 \\
& Psychological Adjustment & 323 & 135.73 & 41.05 \\
\hline
\end{tabular}

Table (1) shows that the average level of overall EI for the sample of the study is 24.45 and its SD is 5.71 at its highest level. It is clear that the mean of the level of the EI for males is 22.05 and its SD is 4.23, while the mean of EI level for females is 26.92 and its SD is 5.98. This means that the EI level for male and females is at its highest level. The chosen sample is taken from academic achievers at higher education institutions in the Sultanate of Oman whether they are SQU students or Staff. SQU accepts the highest scores among the Diploma graduates every year and they constitute $5 \%$ of the population. In addition, SQU provides excellent programs to enrich different aspects of students' personalities. It also indicates that that scale distinguishes the educated and adults from one side and the uneducated young individuals on the other side assuming that the grades of the rest of the community groups differ on the level of maturity and education based on EI scales.

Pearson's Correlation Coefficient is used to answer the second study questions about investigating the relationship between EI, the symptoms of depression and psychological adjustment. (See table 2)

Table 2. Pearson's Correlation Coefficient to investigate the relationship between EI, depressive symptoms and psychological adjustment $(\mathrm{N}=323)$

\begin{tabular}{lllll}
\hline$E I$ & & EI & Depression & Psychological adjustment \\
\cline { 2 - 5 } & $\begin{array}{l}\text { Pearson's } \\
\text { Correlation coefficient }\end{array}$ & 1,000 & $-0,770^{*}$ & $0,767^{*}$ \\
\hline $\mathrm{p}=<0.01$ & & & \\
\hline
\end{tabular}


As can be seen from table (2) there is no inverse relationship between of the level of intelligence and emotional depression, where the coefficient Pearson link - .770 is a function of the level of statistical significance at Alpha equal to 0.01 . This means that when the EI is high, depression goes down in the study sample, and the interpretation of this result can be is that there is a conflict and lack of harmony between EI and symptoms of depression in the sense that EI is the skill of social and emotional capacities which stem from knowledge based on feelings of depression and feelings of sadness. Depression expresses pessimism, negative emotions, and the dissatisfaction with life. Therefore, whenever an individual EI is high, he possesses a greater capacity in overcoming the feelings of depression. The results of this study confirm a study by Ciar-rochi, Deane and Anderson (2002). Also, a study by Martinez-Pons (2003) indicated that individuals who register high levels on the dimensions of the EI scale show higher levels of satisfaction with life and low level on the depression scale.

It is clear from the above table that also there is also a positive correlation between the level of EI and the level of psychological adjustment. The Pearson's Correlation Coefficient reached 0.767 which is statistically significant at Alpha equal to 0.01, in the sense that the higher the level of EI increases the level of psychological adjustment. As is the case for the relationship between negative EI and symptoms of depression, there is a positive relationship between EI and psychological adjustment, where we find that the psychological adjustment is linked positively with EI. One of the positive outcomes generated by EI skills is psychological adjustment. Self-awareness of emotional reactions to the others, they ability to adjust to stress, especially those that cause psychological pressure, dealing with intelligence to overcome them, reducing the level of psychological pressure and depression and achieving a balance between the needs of the individual and the environmental requirements and thus reaching psychological satisfaction. The results of this study supports the study of Saklofske, Austin and Minski (2003) which found that EI is linked positively to satisfaction with life and on the other hand, linked negatively to depression. It also agrees with the study of (Chan, 2005) that recommended the importance of training students to acquire EI skills in the acquisition of the social skills necessary to reduce the level of psychological pressure and depression.

To answer the third question Does gender play a part in the average EI of a person? Special tests have been used to discover the differences in the EI averages of the male and female subjects as shown in table (3).

Table 3. The t-test results indicating the differences in the males and females' EI averages

\begin{tabular}{llllll}
\hline Variable & Gender & $N$ & $M$ & $S D$ & t-value \\
\hline EI & males & 164 & 22.05 & 4.23 & \multirow{2}{*}{$8.47^{*}$} \\
& females & 159 & 26.29 & 5.98 & \\
\hline
\end{tabular}

$* \mathrm{P}=<0.05$

The above table shows that males and females are different in their EI averages. The findings show that females are more emotionally intelligent than males $(t=8.47, \mathrm{p}=0.05)$. The mean and standard deviation values for the female group $(M=26.29, S D=5.98)$ are higher than their male counterparts $(M=22.05, S D=4.23)$. The results agree with many other studies that have proven the common conception of women being better not only in understanding and expressing their emotions but also in understanding others' emotions. In addition, compared to men, women are more capable of expressing themselves and discussing ideas, trends and problems (Suliman \& Dahdhah, 2006). This may be attributed to the biological nature of women and their ways of thinking. The social roles of women may contribute to this as well because women are expected to express their emotions more as mothers. The Arabic cultures that consider muting emotions a sign of manhood can also be a reason behind the results above. 
Table 4. The t-test results indicating the differences in the averages of depressive symptoms attributed to males and females' EI levels (high - low)

\begin{tabular}{lllllll}
\hline Variable & Gender & Level & $N$ & $M$ & $S D$ & t-value \\
\hline Depression & males & low & 60 & 34.12 & 4.63 & $31.45^{*}$ \\
& & high & 104 & 15.90 & 2.80 & \\
& females & low & 46 & 15.50 & 6.32 & $7.12^{*}$ \\
& & high & 113 & 10.67 & 2.24 & \\
\hline
\end{tabular}

$* \mathrm{P}=<0.05$

Table 4 shows that there is a positive correlation between the EI level and the average level of depression of the male participants. That is, the males who are more emotionally intelligent are less depressed. To illustrate, the $t$ (31.45) and the alpha (0.05) values suggest that the men with the higher measures of EI are less depressed $(\mathrm{M}=$ $15.90, \mathrm{SD}=2.80)$ compared to those who are emotionally less intelligent $(\mathrm{M}=34.12, \mathrm{SD}=4.63)$.

The table also presents a similar conclusion about females. The $t(7.12)$ and the alpha $(0.05)$ values are again in favor of the more emotionally intelligent females. The females who are emotionally intelligent measure for depression $(\mathrm{M}=10.67, \mathrm{SD}=2.24)$ as compare to the measures $(\mathrm{M}=15.50, \mathrm{SD}=6.32)$ of females with lower EI.

The strong relationship between depressive symptoms and EI can explain the above results. In other words, being aware of your emotional responses and being able to control them help you to overcome sad emotions and disappointments quickly before they turn into depression. These results confirm the study conducted by Berrocal and his team (2006). Their study has similarly found a positive correlation between EI and positive thinking, and a negative correlation between EI and both anxiety and depression. Such findings make strong evidence to support the significance of skill-based training of EI to reduce the signs of disappointment and sadness before they develop into depression, especially if we believe in the possibility of acquiring these skills just like any other skills.

The fifth question is: Does the level of EI in either males or females affect psychological adjustment? A t-test is used to answer this question.

Table 5. The t-test results indicating the difference in psychological adjustment averages attributed to EI levels (high - low) for males and females

\begin{tabular}{lllllll}
\hline Variable & Gender & Level & $N$ & $M$ & $S D$ & $t$-value \\
\hline Psychological & males & low & 60 & 82.93 & 13.80 & $14.88^{*}$ \\
adjustment & & high & 104 & 128.53 & 21.28 & \\
& females & low & 46 & 134.65 & 35.53 & $6.23^{*}$ \\
& & high & 113 & 170.82 & 32.18 & \\
$* \mathrm{P}=0.05$ & & & & & \\
\hline
\end{tabular}

It is clear from table 5 that there is a link between the level of EI and the level of psychological adjustment among both males and females. The t-value (14.88) suggest that the males with high EI are better adjusted psychologically $(\mathrm{M}=128.53, \mathrm{SD}=21.28)$ than the males with low $\mathrm{EI}(\mathrm{M}=82.93, \mathrm{SD}=13.80)$. The case is the same for the female participants. The t-value of the females (6.23) also help us conclude that females who scored higher in EI have better psychological adjustment $(\mathrm{M}=170.82, \mathrm{SD}=32.18)$, whereas the results of the females with lower $\mathrm{EI}(\mathrm{M}=134.65, \mathrm{SD}=35.53)$ are less psychologically adjusted.

Likewise, the strong connection between psychological adjustment to university life and EI can explain the above findings which constitute considerable evidence of the importance of training of EI skills in acquiring the adjustment skills needed to adapt to university life. What adds to this evidence is knowing that the main traits of psychological adjustment, including emotional awareness of outside reality when evaluating others, and the inside reality when evaluating oneself; expressing their true emotions without inappropriate or excessive responses and strengthening relationships with others, are EI skills. These results agree with the findings of a study done by Salovery and his team (2001) and Salovery (2001). The study revealed that people with low EI 
have weak adjustment skills to different social, emotional, vocational and other aspects of life.

\section{Recommendations}

Based on its findings, this study gives the following recommendations:

1) The strong link between low EI and depressive symptoms calls for intensifying and activating individual and group counseling services which are based on EI practices. Similar to other studies, this study states that the psychological factors related to EI abilities, areas or factors, contribute to increasing or decreasing levels of depression, psychological adjustment and conformity with life.

2) The findings show that the average EI among women is higher than men. This is an indication that more training is needed for males. It also calls for a closer look at the way women acquire their EI skills, and an improved way for raising the level of EI in.

3) Low and high EI were good indicators of both psychological adjustment and depressive symptoms. Therefore, it can be said that these three concepts form a circle, and thus training on EI is a necessity that will lead to positive results, and can also be used to discover some distinguishing abilities, psychological traits and life skills of people.

4) The results of this study encourage conducting more studies on EI, and more pilot studies that provide individual and group counseling services for male and female students who suffer from depressive symptoms and psychological maladjustment to university life.

5) The dimensions, areas and factors of EI, including social skills, should be part of the curricula and syllabuses for both teachers and students. This is necessary to facilitate the learning process as EI does not only facilitate learning; but it also improves vocational choice and success and contributes to successful adjustment to different aspects of life, including adapting to university life.

\section{References}

Al-Dahadha, B., \& Sulaiman, S. (In press). The psychometric characteristics of Wakeman Scale of Emotional Intelligence upon Sultan Qaboos University students in light of study levels. Scientific Journal, King Faysel University, KSA, (V13).

Al-Rihani, S., Hamdi, N., \& Abu-Talib, S. (1989). The relationship between irrational believes and depression among sample of Jordan University students. Derasat (An International Refereed Research Journal), Educational Sciences, University of Jordan, 6(6), 36-55.

Amitay, O. A., \& Mongraion, M. (2007). From Emotional Intelligence to Intelligent Choice of Partner. The Journal of Social Psychology, 147(4), 325-343. http://dx.doi.org/10.3200/SOCP.147.4.325-344

Beck, A. T. (1979). Cognitive Therapy of Depression. New York: The Guilford press.

Berrocal, P., Alcaide, R., \& Extremera, N. (2006). The Role of Emotional Intelligence in anxiety and depression among adolescents. Individual Differences Research, 4(1), 16-27.

Brodsky, S. L. (1988). The Psychology of Adjustment and well-Being. New York, NY: Hoit, Pinehart and Winston, Inc.

Bulik, N. O. (2005). Emotional intelligence in the workplace: Exploring its effects on occupational stress and health outcomes inhuman service workers. International Journal of Occupational Medici and Emotional Health, 18(2), 167-175.

Chan, D. W. (2005). Emotional intelligence, social coping, and psychological distress among Chinese gifted students in Hong Kong. Journal of High Ability Studies, 16(2), 163-178. http://dx.doi.org/10.1080/13598130600617589

Ciar-rochi, J., Deane, F. P., \& Anderson, S. (2002). Emotional intelligence moderates the relationship between stress and mental health. Personality and Individual Differences, 32(2), 197-209. http://dx.doi.org/10.1016/S0191-8869(01)00012-5

Cox, T. (1993). Stress management and stress research: Putting theory to work. HSE Contract Research Report No.61/1993.

Dahadhah. B. (2008). The effectiveness of group counseling in disputing irrational believes and self recurrence in reducing depression and improving self concept for depressed students. Um Alqurq Journal for Educational, Social, And Humanistic Science, 20(1), 1-31.

Derlega, V. G., \& Janda, L. H. (1986). Personal Adjustment: The Psychology of Everyday life. Glenvious. Illinois: 
Scott, Foresman and company.

Edwards, J. R. (1998). Cybernetic theory of stress, coping and well-being. In C. L. Cooper (Ed.), Theories of organizational stress. Oxford: Oxford University Press.

Gardener, H. E. (2000). Intelligence reframed Multiple Intelligences for the 21st Century. New York: Basic Books.

Ghorbani, N. (2006). Religious orientation types in Iranian Muslims: Differences in alexithymia emotional intelligence, self-consciousness, and psychological adjustment. Review of Religious Research, 47(3), 303-310.

Ghorbani, N., Mark, N., Kristl, D., \& Dan, M. (2002). Self-Reported emotional intelligence: Construct similarity and functional dissimilarity of higher- order processing in Iran and the United States. International Journal of psychology, 37(5), 297-308. http://dx.doi.org/10.1080/00207590244000098

Golman. D. (1998). Working with Emotional Intelligence. New York: Ban- tum Books.

Hamdi, N., Abu Hajla, N., \& Abu-Taleb, S. (1988). Construct factors and reliability, validity evidence in the translated Beck Inventory for Depression. Derasat (An International Refereed Research Journal), Educational Sciences, University of Jordan), 15(1), 40-30.

Heesacker, M., \& Bradley, M. M. (1997). Beyond feelings: psychotherapy and emotion. The Counseling Psychologist, 25, 201-219. http://dx.doi.org/10.1177/0011000097252003

Herbert, T. B., \& Choen, S. (1993). Depression and immunity: Amite- analytic review. Psychological Bulletin, 113, 472-486. http://dx.doi.org/10.1037/0033-2909.113.3.472

Jacobson, C., Marrocco, F., Kleinman, M., \& Gould, M. (2011). Restrictive emotionality, depressive symptoms, and suicidal thoughts and behaviours among high school students. Journal of Youth and Adolescence, 40(6), 656-665. http://dx.doi.org/10.1007/s10964-010-9573-y

Khawaldeh, M. (2004). Emotional Intelligence. Amman: Dar Alshorooq for printing and distribution.

Kring, A. M., \& Bachorowski, J. (1999). Emotions and psychopathology. Cognition and Emotion, 13, 575-599. http://dx.doi.org/10.1080/026999399379195

Lazarus, R. S., \& Folkman, S. (1987). Transactional theory and research on emotions and coping. European Journal of Personality, 1, 141-169. http://dx.doi.org/10.1002/per.2410010304

Martinez-Pons, M. (2003). The relation of emotional intelligence with selected areas of personal functioning. Imagination, Cognition and Personality, 17, 3-13. http://dx.doi.org/10.2190/68VD-DFXB-K5AW-PQAY

Mavroveli, S., Petrides, K., Rieffe. C., \& Bakker, F. (2007). Trait emotional intelligence, psychological well-being and peer-rated social competence in adolescence. British Journal of Developmental Psychology, 25(2), 263-275. http://dx.doi.org/10.1348/026151006X118577

Mayer, J. D., \& Salovey, P. (1999). The intelligence of emotional intelligence. Intelligence, 22, 89-113. http://dx.doi.org/10.1016/S0160-2896(96)90011-2

Mayer, J. D., Salovey, P., \& Caruso, D. R. (2002). Mayer-Salovey-Caruso Emotional Intelligence Test (MSCEIT) Item Booklet. Toronto, Canada: MHS Publishers.

Oatley, K., \& Jenkins, J. M. (1998). Understanding Emotions. Oxford, UK: Blackwell.

Parker, J. D. A., Summerfelds, L. J., Hogan, M. J., \& Majeski, S. A. (2004). Emotional intelligence and academic success: Examining the transition from high school to university. Personality and Individual Differences, 36, 163-172. http://dx.doi.org/10.1016/S0191-8869(03)00076-X

Pellitteri, J. (2002). The relationship between emotional intelligence and ego Defense mechanisms. The Journal of Psychology, 136(2), 182-194. http://dx.doi.org/10.1080/00223980209604149

Richburg, M., \& Fletcher, T. (2002). Emotional Intelligence: Directing a child's Emotional education. Child Study Journal, 32(1), 31-38.

Rowe, D. (2001). Depression, the Way Out of Your Prison (2nd ed.). New York: Brunner-Rutledge.

Saklofske, D. H., Austin, E. J., \& Minski, P. S. (2003). Factor structure and validity of a trait emotional intelligence measure. Personality and Individual Differences, 34, 706-721. http://dx.doi.org/10.1016/S0191-8869(02)00056-9

Salguero, J. M., Palomera, R., \& Fernandez-Berrocal, P. (2012). Perceived emotional intelligence as predictor of 
psychological adjustment in adolescents: A 1-year prospective study. European Journal of Psychology of Education, 27(1) 21-34. http://dx.doi.org/10.1007/s10212-011-0063-8

Salovey, P. (2001). Applied emotional intelligence: Regulating emotions to become healthy wealthy, and wise. New York: Psychology Press.

Salovey, P., \& Mayer, J. D. (1990). Emotional intelligence. Imagination Cognition and Personality, 9, 185-211. http://dx.doi.org/10.2190/DUGG-P24E-52WK-6CDG

Salovey, P., Woolery, A., \& Mayer, J. D. (2001). Emotional intelligence: Conceptualization and measurement. In G.J.O Fletcher \& M.S Clark (Eds.) Blackwell Handbook of Social Psychology: Interpersonal Processes (pp.279-307). Malden, MA: Blackwell Publishers.

Slaski, M., \& Cartwright, S. (2003). Emotional intelligence training and its implications its implications for stress, health and Performance. Journal of Stress and Health, 19, 233-239. http://dx.doi.org/10.1002/smi.979

Spector, P. E., \& Oconnell, B. J. (1994). The contribution of personality traits, negative affectivity, locus of control and type A to the subsequent reports of job stressors and job strain. Journal of Occupational and Organizational Psychology, 67, 1-12. http://dx.doi.org/10.1111/j.2044-8325.1994.tb00545.x

Sulaiman, S. M. (1996). Developing and validating an adjustment instrument for college students in sultanate of Oman (Unpublished Doctoral Dissertation). Oregon State University, U.S.A.

Sulaiman, S., \& Al-Dahadha, B. (2006). The level of self disclosure among Sultan Qaboos University students \& some demographic variables. Journal of Educational Sciences (JES)-Qater, 9, 17-49.

Sulaiman, S., \& El-Mneizel, A. F. (1999). Adjustment level among Sultan Qaboos University Student's \& the relationship to sex, class level, grade point average and residency. Derasat (An International Refereed Research Journal), Educational Sciences, University of Jordan, 26(1), 1-18.

Svyantek, D., \& Rahim, M. (2002). Links between emotional intelligence and behavior in organization: findings from empirical studies. International Journal of Organizational Analysis, 10(4), 299-301. http://dx.doi.org/10.1108/eb028954

Tsaousis, I., \& Nikolaou, I. (2005). Exploring the relationship of intelligence with physical and psychological health functioning. Journal of stress and Health, 21, 77-86. http://dx.doi.org/10.1002/smi.1042

Vakola, M., Tsaousis, I., \& Nikolaou, I. (2004). The effects of emotional intelligence and personality variables on attitudes toward organizational change. Journal of Managerial Psychology, 19, 88-110. http://dx.doi.org/10.1108/02683940410526082

Vander Voort, D. J. (2006). The importance of emotional intelligence in Higher Education. Journal of Current Psychology: Developmental Learning, Personality, $\quad$ Social, $\quad$ 25(1), 4-7. http://dx.doi.org/10.1007/s12144-006-1011-7

Wakeman, C. (2006). Emotional intelligence testing, measurement and analysis. Research in Education, 75(1), 71-93. http://dx.doi.org/10.7227/RIE.75.6

Watkins, C. E. (1997). Handbook of Psychotherapy Supervision. New York: John Wiley \& Sons, Inc.

Wolman, B. B. (1989). Dictionary of Behavior Science (2nd ed.). New York, NY: Academic Press, Inc.

\section{Copyrights}

Copyright for this article is retained by the author(s), with first publication rights granted to the journal.

This is an open-access article distributed under the terms and conditions of the Creative Commons Attribution license (http://creativecommons.org/licenses/by/3.0/). 